\title{
Aktivitas Antifungi Esktrak Etanol Daun Kamboja Merah (Plumeria rubra L.) Terhadap Pityrosporum ovale
}

\author{
Antifungal Activity of Plumeria rubra L. Ethanolic Leaves Extract Against \\ Pityrosporum ovale
}

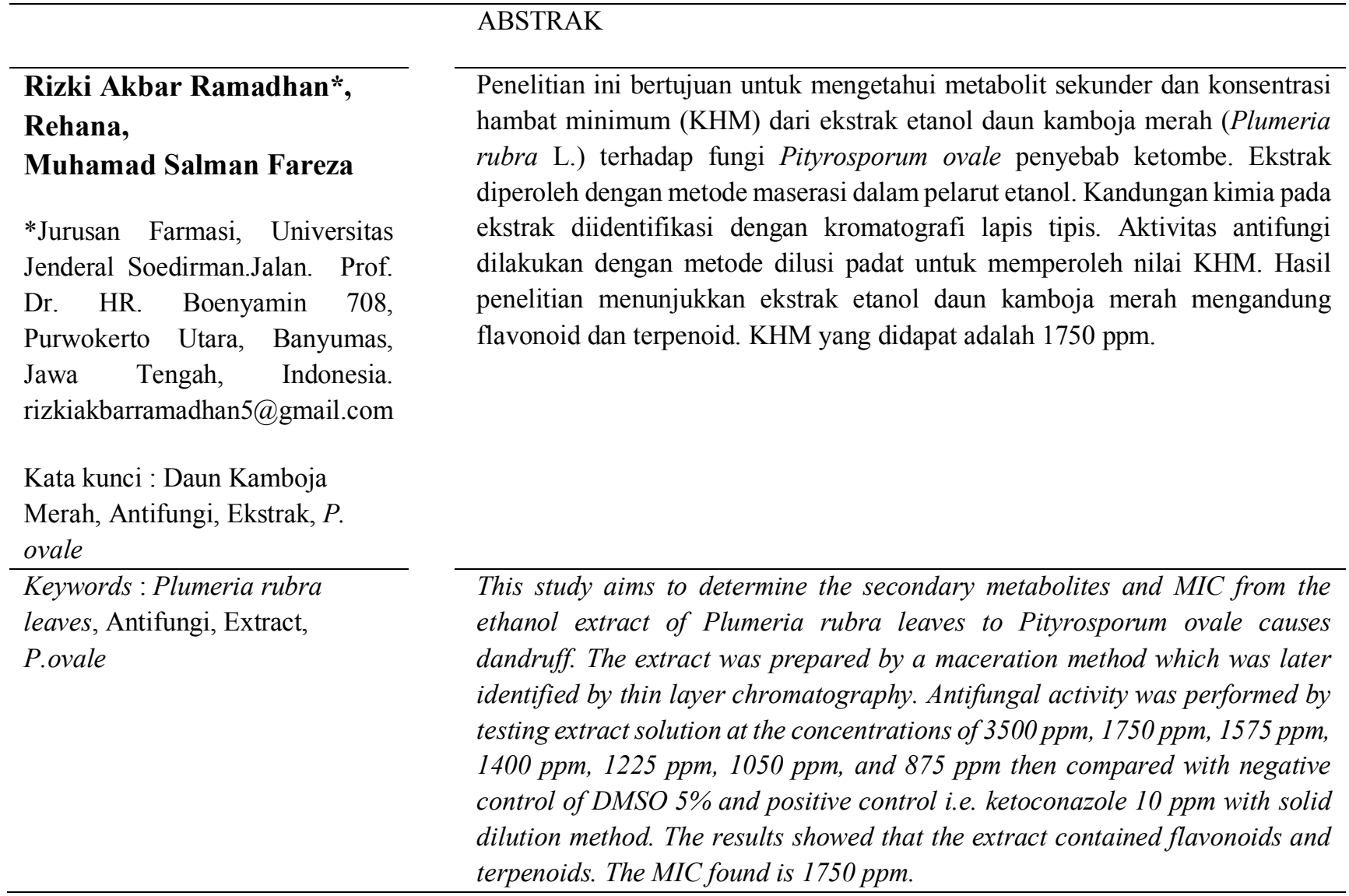

\section{Pendahuluan}

Ketombe merupakan infeksi mikroorganisme atau adanya pengeluaran kelenjar keringat yang berlebihan di kulit kepala yang salah salah satunya disebabkan oleh fungi Pityrosporum ovale (Cappuccino, 2013). Pengobatan masalah ketombe hingga saat ini biasanya menggunakan zat aktif bahan kimia seperti ketokonazol, zinc pyrithione (ZPT), dan selenium sulfida yang terdapat dalam bentuk sediaan shampo. Selain bahan kimia, beberapa penelitian telah melaporkan penggunaan bahan-bahan alam sudah mulai dikembangkan sebagai alternatif untuk mengatasi permasalahan ketombe. Salah satu tanaman memiliki potensi untuk diteliti sebagai antifungi $P$. ovale adalah kamboja merah (Plumeria rubra).
P. rubra merupakan tanaman dari famili Apocynaceae yang berasal dari daerah tropis Amerika (Manisha dan Aher, 2016). Secara empiris daun tanaman ini digunakan untuk mengobati berbagai penyakit seperti peradangan, rematik, bronkhitis, batuk, kolera, disepsia, dan demam (Rekha dan Jayakar, 2011). Daun kamboja merah dilaporkan memiliki kandungan seperti flavonoid, alkaloid, tanin, dan terpenoid. Selain itu, ekstrak daun kamboja merah juga telah dilaporkan memiliki aktivitas antibakteri, antijamur, dan antikanker (Baghel et al., 2010; Rekha dan Jayakar, 2011; Jarin et 
al., 2008). Sebagai antijamur, daun kamboja merah juga sudah diteliti dapat menghambat pertumbuhan beberapa fungi seperti Candida albicans, Aspergillus niger, Aspergillus ustus dan Aspergillus ochaceus (Jarin et al, 2008). Saat ini belum ada laporan potensi dari ektrak etanol yang berasal daun kamboja merah sebagai antijamur $P$. ovale. Oleh karena itu, kami melakukan penelitian mengenai uji aktivitas antifungi $P$. ovale dari ekstrak daun kamboja merah.

\section{Bahan dan Metode}

\section{Bahan}

Daun kamboja merah, etanol $70 \%$, metanol p.a, $\mathrm{CHCl}_{3}$ p.a., plat silika gel $60 \mathrm{~F}_{254}$, pereaksi Dragendroff, peraksi sitroborat, larutan $\mathrm{H}_{2} \mathrm{SO}_{4} \quad 10 \%$, media Sabouraud Dextrose Agar (SDA), $\mathrm{NaCl}$ p.a, DMSO p.a., isolat fungi P. oryzae, ketokonazol p.a.

\section{Ekstraksi dan uji fitokimia}

Sebanyak $2 \mathrm{~kg}$ serbuk daun kamboja merah yang berasal dari Purwokerto dibuat dengan metode maserasi selama $3 \times 24$ jam menggunakan pelarut etanol $70 \%$. Setelah itu, diidentifikasi dengan kromatografi lapis tipis menggunakan fase diam plat silika gel $60 \mathrm{~F}_{254}$ dan fase gerak eluen klorofom dan metanol 9:1, kemudian disemprot menggunakan pereaksi dragendroff, sitroborat, dan $\mathrm{H}_{2} \mathrm{SO}_{4} 10 \%$ (Wagner dan Bladt, 1996).

\section{Uji aktivitas antifungi}

Uji aktivitas antifungi dilakukan dengan metode dilusi padat menggunakan media Sabouraud Dextrose Agar (SDA). Pengujian dilakukan dengan cara membuat larutan uji dari ekstrak dengan konsentrasi 3500 ppm, 1750 ppm, 1575 ppm, 1400 ppm, 1225 ppm, 1050 ppm, dan 875 ppm. Selanjutnya, membuat suspensi fungi dengan mengambil isolat fungi P.ovale kemudian dilarutkan dalam larutan $\mathrm{NaCl} \quad 0,9 \%$ yang disesuaikan kekeruhannya dengan larutan standar McFarland 0,5. Penggunaan kontrol negatif menggunakan larutan DMSO 5\% sedangkan kontrol positif menggunakan ketokonazol $10 \%$, diinkubasi $2 \times 24$ jam kemudian diamati pertumbuhan funginya.

\section{Analisis data}

Data disajikan secara deskriptif dari hasil metabolit sekunder dan nilai KHM yang didapatkan.

\section{Hasil dan Pembahasan}

\section{Ekstraksi dan uji fitokimia}

Berdasarkan proses ekstraksi yang dilakukan diperoleh rendemen dari hasil ektraksi sebesar 0,217 g ekstrak sebesar $10,86 \%$. Hasil uji identifikasi kandungan ekstrak etanol daun kamboja merah yaitu positif mengandung flavonoid setelah plat klt disemprot dengan pereaksi sitroborat timbul bercak berwarna biru, kuning tua, atau hijau yang berflourosensi dibawah $\mathrm{UV}_{366}$ (Wagner dan Bladt, 1996). Hasil tersebut sama seperti plat berisi standar Rutin yaitu nilai rf dan timbul warna yang sama (Gambar 1).

Pada uji kandungan terpenoid, ekstrak etanol memperlihatkan positif mengndung terpenoid karena setelah disemprot pereaksi $\mathrm{H}_{2} \mathrm{SO}_{4} 10 \%$ timbul bercak berwarna biru, kuning, dan cokelat (Gambar 2) (Wagner dan Bladt, 1996). 


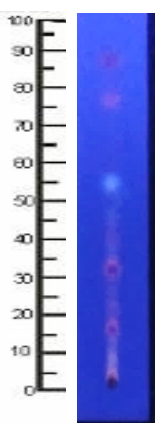

(A)

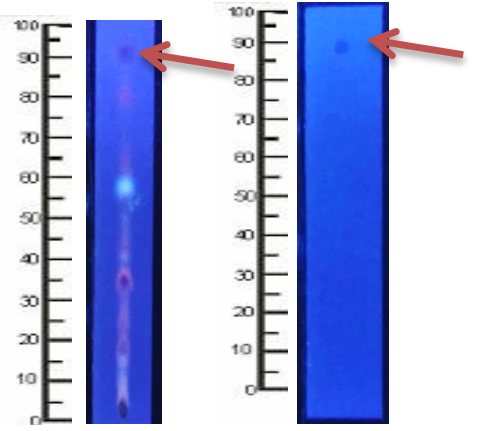

(B)

(C)
Gambar 1. Profil KLT uji flavonoid. (A) Profil KLT uji flavonoid yang diamati dibawah $\mathrm{UV}_{366}$ sebelum disemprot sitroborat, (B) Profil KLT uji flavonoid yang diamati dibawah $\mathrm{UV}_{366}$ setelah disemprot sitroborat, (C) Profil KLT Rutin. Fase diam menggunakan silika gel $60 \mathrm{~F}_{254}$ dan fase gerak menggunakan klorofom : metanol (9:1), Plat KLT diamati dibawah sinar UV366

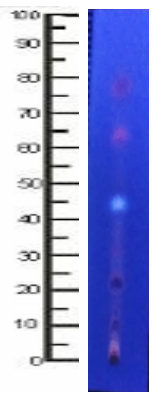

(A)

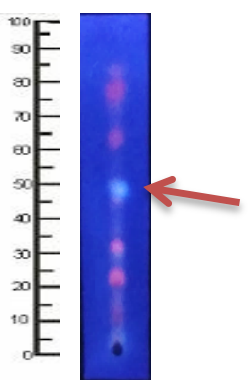

(B)
Gambar 2. Profil KLT uji terpenoid. (A) Profil KLT uji terpenoid yang diamati dibawah $\mathrm{UV}_{366}$ sebelum disemprot $\mathrm{H}_{2} \mathrm{SO}_{4} 10 \%$. (B) Profil KLT uji terpenoid yang diamati dibawah $\mathrm{UV}_{366}$ setelah disemprot $\mathrm{H}_{2} \mathrm{SO}_{4} 10 \%$. Fase diam menggunakan silika gel 60F254 dan fase gerak menggunakan klorofom : metanol (9:1), plat KLT diamati dibawah sinar UV 366

Pada uji kandungan alkaloid, ekstrak pada senyawa alkaloid tidak terdapat bercak berwarna jingga setelah disemprot pereaksi dragendroff sehingga hasilnya ekstrak etanol daun kamboja merah yang berasal dari Purwokerto negatif mengandung senyawa alkaloid. Ramproshad et al. (2012) telah melaporkan bahwa tanaman P. lubra yang berasal dari Bangladeh mengandung alkaloid.

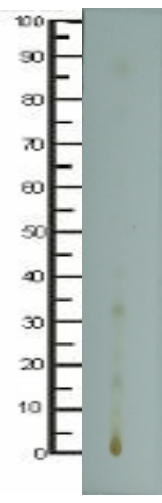

(A)

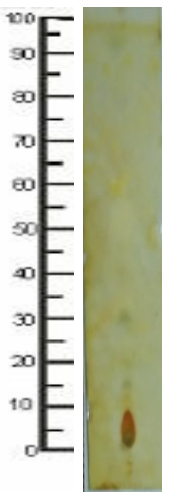

(B)
Gambar 3. Profil KLT uji alkaloid (A) Profil KLT uji alkaloid sebelum disemprot reagen dragendroff, (B) Profil KLT uji alkaloid setelah disemprot reagen dragendroff. Fase diam menggunakan silika gel $60 \mathrm{~F}_{254}$ dan fase gerak menggunakan klorofom : metanol (9 : 1), Plat KLT diamati dibawah sinar tampak

Hasil uji aktivitas antifungi menunjukkan adanya penghambatan pada konsentrasi 3500 ppm dan 1750 ppm ditandai dengan tidak ada pertumbuhan fungi pada cawan petri sedangkan pada konsentrasi 1575 ppm, 1400 ppm, 1225 ppm, 1050 ppm dan $875 \mathrm{ppm}$ terlihat adanya pertumbuhan fungi.

Hasil KHM menunjukkan tidak terdapat pertumbuhan P.ovale pada konsentrasi 1750 ppm (Gambar 4) Hasil tersebut dapat dikategorikan bahwa ekstrak etanol daun kamboja merah memiliki aktivitas antifungi kuat, karena memiliki daya hambat dibawah kosentrasi 5000 ppm (Bussman R.W. et al., 2010) 


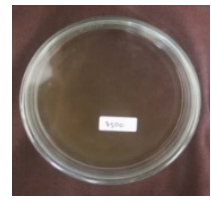

(A)

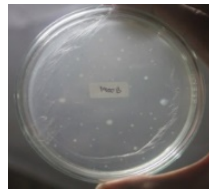

(D)

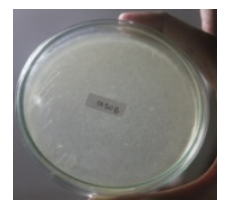

(G)

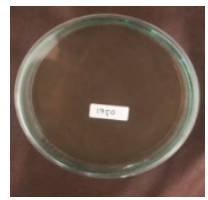

(B)

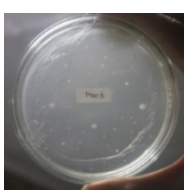

(E)

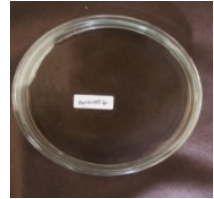

(H)

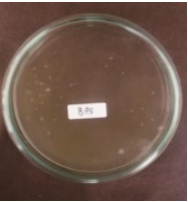

(C)

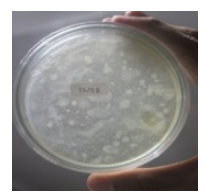

(F)

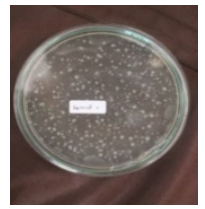

(I)
Gambar 4. Cawan petri berisi konsentrasi 3500 ppm (A), 1750 ppm (B), 875 ppm (C), 1575 ppm (D), 1400 ppm (E), 1225 ppm (F), 1050 ppm (G), kontrol positif ketokonazol 10\% $(\mathrm{H})$, dan kontrol negatif DMSO 5\% (I).

\section{Simpulan}

Ekstrak etanol daun kamboja merah (Plumeria rubra L) asal Purwokerto memiliki kandungan flavonoid dan terpenoid. Kadar Hambat Minimum (KHM) ekstrak etanol daun kamboja merah (Plumeria rubra L) didapatkan pada konsentrasi 1750 ppm terhadap fungi Pityrosporum ovale.

\section{Daftar Pustaka}

Baghel, A.S., Mishra, C.K., Rani, A., Sasmal, D., Nema, R.K, 2010, Antibacterial activity of Plumeria rubraLinn. plant extract, Journal of Chemical and Pharmaceutical Research, 2(6):435-440.

Bussman, R.W., Malca-García, G., Glenn, A., Sharon, D., Chait, G., Díaz, D., Pourmand, K., Jonat, B., Somogy, S., Guardado G., Aguirre, C., Chan, R., Meyer, K., Kuhlman,
A., Townesmith, A., Effio-Carbajal, J., Frías-Fernandez, F., Benito, M., 2010, Minimum inhibitory concentrations of medicinal plants used in Northern Peru as antibacterial remedies, Journal of Ethnopharmacology 132 (10) : 101108.

Cappuccino, J. G., 2013, Manual Laboratorium Mikrobiologi Edisi 8., diterjemahkan July Manurung, Henrita Vidhayanti, EGC, Jakarta, 229.

Jarin, L., Rahman S.MD, dan Anwar, M.N., 2008, Antibacterial And Antifungal Activity Of Crude Extracts Of Plumeria rubra L., The Chittagong University Journal of Biological Sciences, 3 (1 \& 2 ): 87-94.

Manisha, K. dan Aher, A.N., 2016, Review on traditional medicinal plant: Plumeria rubra, Journal of Medicinal Plants Studies 4(6): 204207.

Wagner, H., dan Bladt, S., 1996, Plant Drug Analysis, A thin layer Chromatography Atlas, Spinger, Heidelberg, 396-397.

Ramproshad, S., Afroz, T., Mondal, B., Khan, R., Ahmed, S., 2012, Screening of Phytochemical and Pharmacological activities of leaves of medicinal plant Plumeria rubra, International journal of research in pharmacy and chemistry, 2012, 4: 1001-1007.

Rekha, J.B., dan Jayakar, B., 2011, Anti cancer activity of ethanolic extract of Leaves of Plumeria rubra (Linn). Current Pharma Research, 1(2): 175-179. 